\title{
CLINICOEPIDEMIOLOGICAL PROFILE OF PITYRIASIS VERSICOLOR IN A TERTIARY CARE HOSPITAL IN KATHMANDU, NEPAL
}

\author{
Shrestha S, Koirala P, Timothy U
}

Department of Dermatology, Nepal Medical College Teaching Hospital, Attarkhel, Gokarneshwor-8, Kathmandu, Nepal

\begin{abstract}
Pityriasis versicolor (PV) also known as Tinea versicolor is a benign, chronic superficial fungal infection of the skin caused by Malassezia furfur. It is characterized by dyspigmented macules with fine branny scales. The purpose of this study was to assess the epidemiological profile and clinical pattern of PV in a group of patients visiting a tertiary care centre of Nepal. A descriptive cross-sectional study was carried out including 150 patients diagnosed to have PV at the outpatient dermatology department of Nepal Medical College Teaching Hospital. Patients with the diagnosis of PV were included in the study. A detailed history was taken and it was followed by a thorough clinical examination. The findings of history and clinical examinations were documented in a predesigned proforma. Statistical Package for the Social Sciences (SPSS) version 16 was used to tabulate the data and analyze the results. There was a slight male preponderance with maximum patients of the age group $11-20$ years. A majority of patients were students. Forty three (28.7\%) patients had similar problem in close contacts and $42 \%$ had recurrent disease. Wearing of occlusive synthetic clothing was the commonest predisposing factor. Upper chest and upper back were the most involved sites. Hypopigmented macules were the commonest lesions in $72.7 \%$. Coexisting seborrheic dermatitis (commonly pityriasis capitis ) was present in $44.67 \%$ of patients. Clinicoepidemiological profile of PV in our setting is similar to many studies done mostly in India. But few findings differ which indicates the need for further studies in Nepal especially from Terai regions where the prevalence is expected to be more.
\end{abstract}

\section{KEYWORDS}

Clinicoepidemiological, pityriasis versicolor, Nepal

\section{CORRESPONDING AUTHOR}

Dr. Shristi Shrestha,

Associate Professor, Department of Dermatology,

Nepal Medical College Teaching Hospital,

Attarkhel, Gokarneshwor-8, Kathmandu, Nepal

Email: drshristi@nmcth.edu

ORCID ID: 0000-0002-3395-7824

DOI: https://doi.org10.3126/nmcj.v21i4.27625 


\section{INTRODUCTION}

Pityriasis versicolor (PV) also known as Tinea versicolor (TV) is a benign, chronic superficial fungal infection of the skin caused by Malassezia yeasts which are part of the many microscopic organisms that normally live on the skin. ${ }^{1}$ It is characterized by discolored or depigmented, discrete or confluent scaly areas mostly involving the upper trunk. ${ }^{2}$ Epidemiologically, PV is more frequently seen in people residing in tropical regions with prevalence as high as $40 \%$ whereas in temperate areas the prevalence is lower. ${ }^{3}$ The point prevalence of PV in Nepal has been reported to be $8.9 \% .{ }^{4}$ Several factors are associated with increased risk of acquiring PV, like increased environmental humidity, application of oily preparation and creams (due to lipophilicity of the organism), corticosteroid overuse, genetic predisposition, malnutrition and hyperhidrosis. ${ }^{5}$ Age wise, late teens and young adults have the increased risk of $\mathrm{PV}^{6-16}$ Though PV is pretty common in Nepal, very few studies have been conducted to look into the epidemiological and clinical characteristics of this disease. Besides, due to widely varying environmental factors, epidemiological and clinical profile of PV is expected to vary from one geographic location to another. Hence, this study was done with the aim of finding out the epidemiological profile, common predisposing factors and clinical profile of PV in Nepalese people.

\section{MATERIALS AND METHODS}

A descriptive cross-sectional study was carried out at the outpatient dermatology department of Nepal Medical College Teaching Hospital for a period of 18 months from January 2018 to June 2019. The sample size was calculated using the formula $n=Z^{2} p(1-p) / d^{2}$ where $n=$ sample size, $Z$ $=$ reliability coefficient ( 1.96 for $95 \%$ confidence interval), $\mathrm{p}=9 \%$ (Point prevalence in Nepal in a study done by Walker et al was $8.9 \%)^{4}$ and d $=$ Absolute error ( $5 \%$ taken for this study). The study group comprised of 150 patients diagnosed as PV by a dermatologist. Patients presenting with hypopigmented or hyperpigmented macules with fine powdery branny scales were seen by a dermatologist. The macules were examined using a Wood's lamp and presence of yellow to golden yellow fluorescence was considered diagnostic of PV; and these patients were included in the study. A verbal consent was taken from all the patients at the time of diagnosis to include them in the study.

A detailed history was taken in a predesigned proforma which included patient's age, sex, occupation, duration, itching, history of recurrence, climatic influence, starting season, history of similar problem in family or contact, sharing of clothings, use of synthetic clothing and use of oil or talcum powder. A thorough clinical examination was done to determine the complexion of the patient, distribution of the skin lesions, color of the skin lesions and presence of seborrheic dermatitis (including pityriasis capitis or dandruff). The findings of history and clinical examinations were documented in the proforma. Statistical Package for the Social Sciences (SPSS) version 16 was used to tabulate the data and analyse the results. Ethical clearance was taken from the Nepal Medical College Institutional Review Committee.

\section{RESULTS}

Out of the total 150 patients having PV, 84 (56.0\%) were male and $66(44.0 \%)$ were female with a slight male preponderance (M:F=1.27:1). Maximum numbers of patients belonged to the age group 11 to 20 years (43.3\%), followed by 21 to 30 years (32.0\%). Only $2.7 \%$ were more than 50 years of age (Fig. 1).

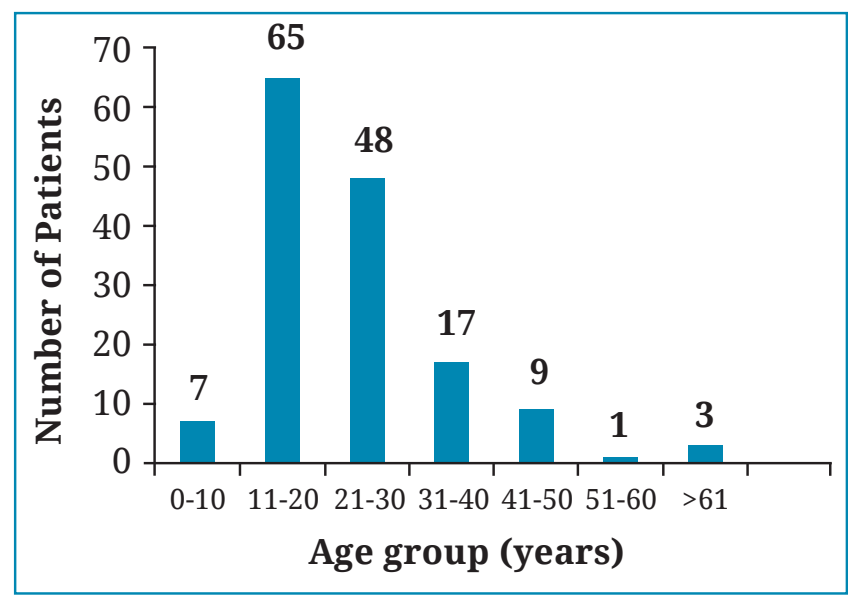

Fig. 1: Distribution of patients according to age group

The disease was most common in students (52\%), followed by housewives $(20.0 \%)$ (Table 1$)$. The duration of disease ranged from 1 week up to 350 weeks. It was less than 1 month in 43 patients (28.67\%), 1 to 12 months in 87 patients (58.0\%), 1 to 2 years in $10(6.67 \%)$ and more than 2 years in 10 patients (6.67\%) (Fig. 2). Eighty seven (58.0\%) patients said it was the first episode while 63 patients (42.0\%) had recurrent disease. In $73.3 \%$ of the patients PV started in the summer season. History of similar disease in family members or close contacts was present in only 43 patients (28.7\%). Fifty three (35.3\%) patients gave history of sharing clothes with family or friends. Minimal number of patients used talcum powder (4.7\%) and oil (14.7\%). Fifty nine (39.3\%) agreed to wearing synthetic clothing regularly. 


\begin{tabular}{|lcc|}
\hline \multicolumn{3}{|c|}{ Table 1: Distribution of patients according to } \\
occupation
\end{tabular}

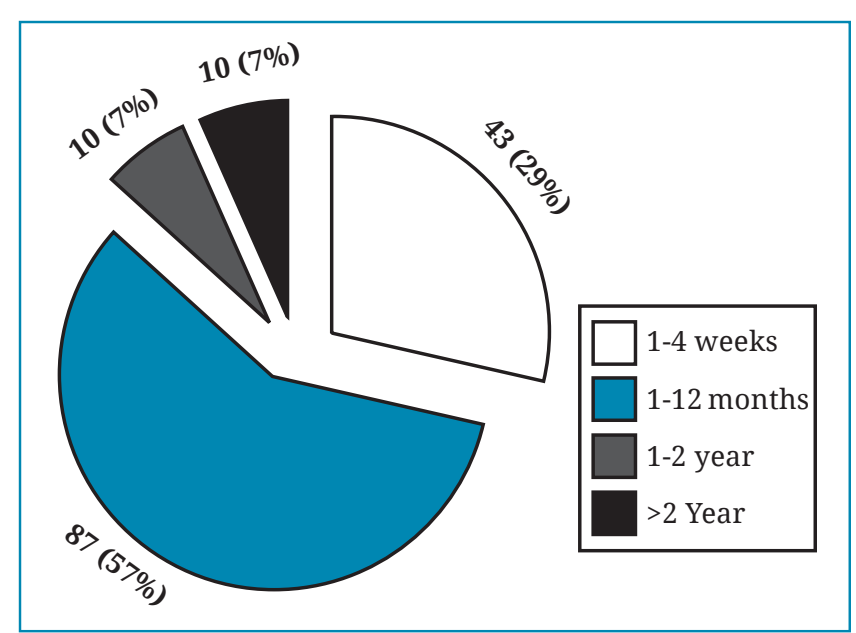

Fig. 2: Distribution of patients according to duration of disease

Fifty-five patients (36.7\%) complained of itching. Most of the patients had olive skin complexion (55.3\%), followed by fair complexion in 31.3\% and dark complexion in $13.3 \%$. Only one site was involved in 38 (25.3\%), and multiple sites were

\begin{tabular}{|c|c|c|c|c|c|c|c|c|c|c|c|c|c|c|c|c|}
\hline \multirow{2}{*}{$\begin{array}{l}\text { Age group } \\
\text { Sites }\end{array}$} & \multicolumn{2}{|c|}{ Total } & \multicolumn{2}{|c|}{$\begin{array}{l}0-10 \\
\text { years }\end{array}$} & \multicolumn{2}{|c|}{$\begin{array}{l}11-20 \\
\text { years }\end{array}$} & \multicolumn{2}{|c|}{$\begin{array}{l}21-30 \\
\text { years }\end{array}$} & \multicolumn{2}{|c|}{$\begin{array}{l}31-40 \\
\text { years }\end{array}$} & \multicolumn{2}{|c|}{$\begin{array}{l}41-50 \\
\text { years }\end{array}$} & \multicolumn{2}{|c|}{$\begin{array}{l}51-60 \\
\text { years }\end{array}$} & \multicolumn{2}{|c|}{$\begin{array}{c}>61 \\
\text { years }\end{array}$} \\
\hline & $\mathbf{n}$ & $\%$ & $\mathbf{n}$ & $\%$ & $\mathrm{n}$ & $\%$ & $\mathbf{n}$ & $\%$ & $\mathbf{n}$ & $\%$ & $\mathbf{n}$ & $\%$ & $\mathbf{n}$ & $\%$ & $\mathbf{n}$ & $\%$ \\
\hline Face & 22 & 5.91 & 3 & 15.79 & 10 & 6.22 & 5 & 4.51 & 1 & 2.27 & 2 & 8.33 & 0 & 0 & 1 & 16.67 \\
\hline Neck & 40 & 10.75 & 2 & 10.53 & 18 & 11.18 & 12 & 10.8 & 3 & 6.82 & 3 & 12.5 & 1 & 14.29 & 1 & 16.67 \\
\hline $\begin{array}{l}\text { Upper } \\
\text { chest }\end{array}$ & 98 & 26.35 & 5 & 26.32 & 43 & 26.71 & 31 & 27.93 & 9 & 20.45 & 7 & 29.17 & 1 & 14.29 & 2 & 33.33 \\
\hline Abdomen & 18 & 4.84 & 1 & 5.26 & 8 & 4.97 & 4 & 3.6 & 4 & 9.1 & 0 & 0 & 1 & 14.29 & 0 & 0 \\
\hline $\begin{array}{l}\text { Upper } \\
\text { back }\end{array}$ & 98 & 26.35 & 4 & 21.05 & 44 & 27.32 & 33 & 29.73 & 11 & 25 & 5 & 20.83 & 1 & 14.29 & 0 & 0 \\
\hline $\begin{array}{l}\text { Lower } \\
\text { back }\end{array}$ & 24 & 6.45 & 2 & 10.53 & 11 & 6.83 & 7 & 6.31 & 2 & 4.55 & 1 & 4.17 & 1 & 14.29 & 0 & 0 \\
\hline $\begin{array}{l}\text { Upper } \\
\text { arm }\end{array}$ & 45 & 12.1 & 1 & 5.26 & 18 & 11.18 & 12 & 10.81 & 8 & 18.18 & 3 & 12.5 & 1 & 14.29 & 2 & 33.33 \\
\hline Forearm & 20 & 5.37 & 1 & 5.26 & 6 & 3.73 & 5 & 4.51 & 5 & 11.36 & 2 & 8.33 & 1 & 14.29 & 0 & 0 \\
\hline Others & 7 & 1.88 & 0 & 0 & 3 & 1.86 & 2 & 1.8 & 1 & 2.27 & 1 & 4.17 & 0 & 0 & 0 & 0 \\
\hline Total & 372 & 100 & 19 & 100 & 161 & 100 & 111 & 100 & 44 & 100 & 24 & 100 & 7 & 100 & 6 & 100 \\
\hline
\end{tabular}

Table 3: Distribution of patients according to complexion of skin and color of skin lesions

\begin{tabular}{|c|c|c|c|c|c|c|c|c|}
\hline \multirow[t]{3}{*}{ Complexion of patients } & \multicolumn{6}{|c|}{ Color of skin lesions } & \multirow{3}{*}{ Total } & \multirow{3}{*}{ P-value } \\
\hline & \multicolumn{2}{|c|}{$\begin{array}{c}\text { Hyperpigmentation } \\
\text { only }\end{array}$} & \multicolumn{2}{|c|}{ Both } & \multicolumn{2}{|c|}{$\begin{array}{l}\text { Hypopigmentation } \\
\text { only }\end{array}$} & & \\
\hline & $\mathbf{n}$ & $\%$ & $\mathbf{n}$ & $\%$ & $\mathbf{n}$ & $\%$ & & \\
\hline Dark & 5 & 25.0 & 4 & 20.0 & 11 & 55.0 & 20 & 0161 \\
\hline Olive & 16 & 19.3 & 12 & 14.5 & 55 & 66.3 & 83 & 0.164 \\
\hline Fair & 18 & 38.3 & 7 & 14.9 & 22 & 46.8 & 47 & \\
\hline
\end{tabular}




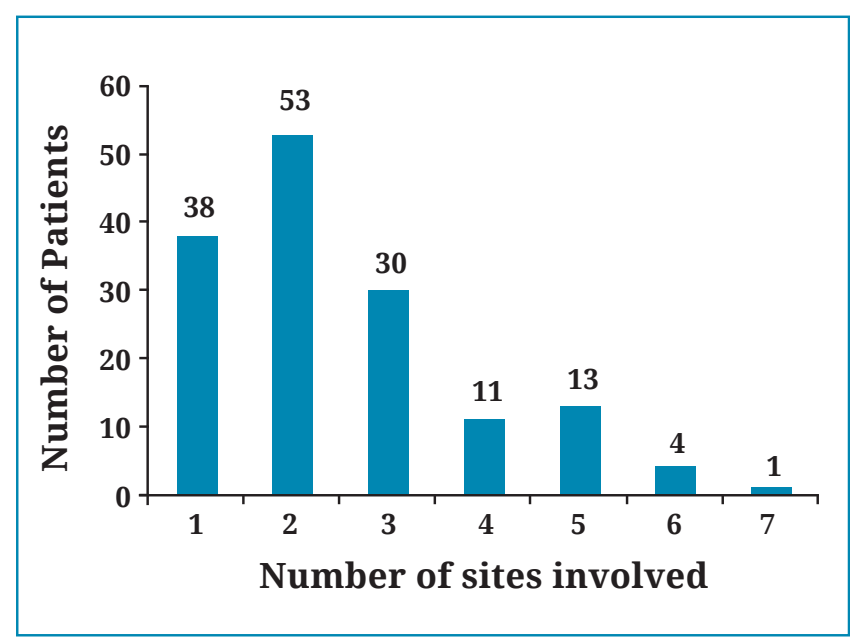

Fig. 3: Distribution of patients according to the number of sites involved

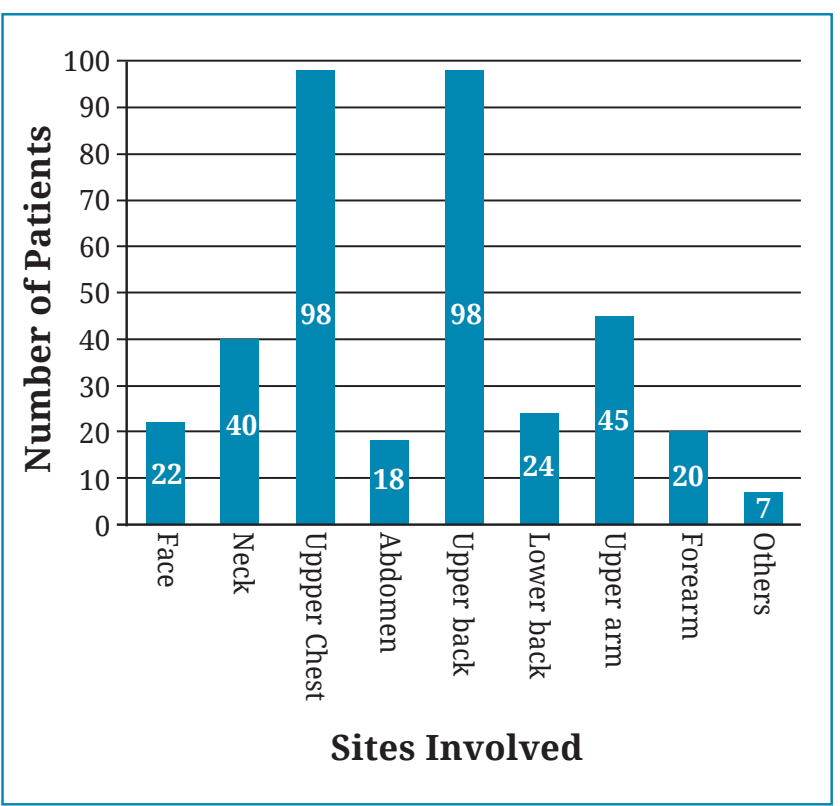

Fig. 4: Distribution of patients according to sites involved

involved in remaining 112 (74.7\%) of the patients (Fig. 3). In 150 patients total 376 sites were involved. Upper chest and upper back were the commonest sites involved which formed $26.06 \%$ of all the sites involved. The other sites involved were upper arm (12.1\%), neck (10.75\%), face (5.91\%), lower back (6.45\%), forearm (5.37\%), abdomen (4.84\%) and others (1.88\%). Others included 2 sites - axilla (1.07\%) and thigh (0.81\%) (Fig. 4). In the age groups 0-10 years, $41-50$ years and >61 years upper chest was the commonest site involved whereas in age groups 11-20 years, 21-30 years and 31-40 years upper back was the commonest site involved. In the age group 5140 years neck, upper chest, abdomen, upper back, lower back, upper arm and forearm were involved in equal percentages (Table 2).

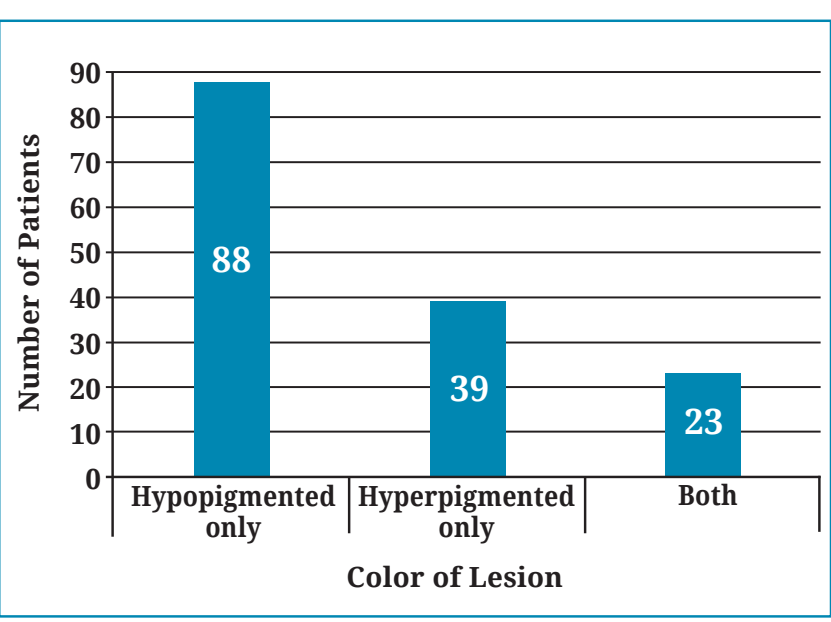

Fig. 5: Distribution of patients according to color of lesion

Morphologically, most of the lesions were hypopigmented macules (72.7\%) whereas hyperpigmented macules were seen in $40.0 \%$. Only hypopigmented macules were seen in $58.7 \%$ and only hyperpigmented macules were present in $26.0 \%$ of patients. However, both hypopigmented and hyperpigmented macules were detected in $15.3 \%$ of patients (Fig. 5). Individuals with dark, olive and fair complexion had more of hypopigmented lesions (55\%, 66.3\% and $46.8 \%$ respectively) and it was statistically not significant $(\mathrm{p}$-value $=0.164)($ Table 3$)$. Coexisting seborrheic dermatitis was present in 67 patients (44.67\%), out of which 56 patients had milder form i.e. pityriasis capitis.

\section{DISCUSSION}

Few of the results in our study were in concordance with previous studies but few facts differed. In our study there was a male preponderance (M:F $=1.27: 1$ ) and this was concordant with many other studies. ${ }^{6-8,11-18}$ It is a well understood fact that men are involved in lots of outdoor activities because of which the hot and humid environment predisposes them to develop PV. In our study, there was only a slight preponderance in male which could be explained by the fact that females are more concerned about the appearance of their skin; and also in our community PV is confused with vitiligo, so that fear makes them consult a doctor immediately. In contrast to our studies, few studies have shown PV to be more common in female. ${ }^{9,19}$ Studies by Kaur et $a l^{21}$ and Tarazoorie et $a l^{20}$ have shown that there are no differences in development of PV among both sexes and there is overall consensus that persons of either sex are equally likely to develop this infection.

PV commonly is a disease of teenagers and young adults. In our study also, the commonest age group was $11-20$ years followed by $21-30$ years. Similar 
finding was noted in a study by Ghosh et al (11-20 years), Santana et al (10 - 19 years) and Morais et al (10 - 20 years).$^{6,9,11}$ In several other studies it was found that 21 - 30 years was the commonest age group involved. . $, 8,12,15,16,18,20,21$ But in contrast to these studies, Kambil and Thayikkannu et al have reported it to be commonest in $20-40$ years. ${ }^{14,19}$ The fact that Malassezia yeasts (the causative organism of PV) is lipophilic ${ }^{5}$; and that in adolescence and young adults there are hormonal changes with excessive activity of sebaceous glands, explains why this disease is common in this age group of $11-30$ years. ${ }^{3}$ Besides, the other factor could be the trend of wearing occlusive synthetic clothing in the young generation today which could also act as predisposing factor. Childhood PV ( $<10$ years) was seen in only $4.7 \%$ and only $2.7 \%$ of patients constituted more than 50 years. Many studies have found that PV is less common in children, $7,8,11,14,15,19,20$ but in a study by Rijal et al in children of age group 0-14 years, the prevalence of PV was $56.4 \%$ of all hypopigmented macules screened. ${ }^{23}$ In another study by Dwari et $a l$, it was reported that $31 \%$ of the total cases of PV belonged to age group $0-14$ years and $4.8 \%$ of patients were infants. ${ }^{24} \mathrm{PV}$ was found to be rare in people older than 50 years like in many other studies. $6,8,11,13,20$

In our study, the students were most commonly affected by PV which is similar to other studies by Ghosh et al, Rao et al, Morais et al, Shah et $a l$, Kambil and Devendrappa et al.6,8,11,12,14,18 This explains the fact why the adolescents and young adults are commonly involved. Besides they are also involved in lots of outdoor activities because of which sweating and sun can predispose them to develop this disease. Also, it was found that $28 \%$ of the patients in the age group 11 to 40 years used to share clothing and $30.65 \%$ of these patients wore occlusive synthetic clothing frequently. Housewives were the second most commonly affected similar to studies by Shah et al and Kambil. ${ }^{12,14}$ For them the consultation would be important because of the aesthetic issue. In Nepal, there are lots of social stigma associated with vitiligo and many times the patients confuse PV with vitiligo and they consult a specialist only to clear that confusion.

The duration of disease ranged from 1 week up to 7 years which was similar to few other studies. ${ }^{6,13,14}$ But in studies by Sharma et al and Banerjee et al up to 20 years duration has been recorded. ${ }^{7,10}$ The recurrence rate of the disease was $42 \%$ which was comparable to the recurrence rate reported in many other studies ranging from $23.75 \%$ to $55.2 \%{ }^{9-11,14,19}$

PV is known to occur more frequently in tropical climates and summer months. ${ }^{25}$ Different studies conducted in different parts of the world have shown that PV is commonly seen in summer season. $^{6-8,14}$ In our study also $73.3 \%$ of the patients had the lesions starting in summer months.

$\mathrm{PV}$ is considered to be a contagious disease, so presence of similar problem in family is considered to be one of the predisposing factors. In various studies, the family history was present in $6 \%, 16.8 \%, 25.5 \%, 34.22 \%, 38.3 \%$ and $44.8 \% .^{6-}$ $8,11,14,24$ and in our study $28.7 \%$ of patients gave history of similar disease in family members or close contacts. But in a study by Rao et al, spreading from parents to children has been seen to be more $(13.3 \%)$ than spread among spouses (10\%) and he has stated that hereditary factor may play role in the transmission of disease. ${ }^{8}$

Overgrowth of the commensal fungus Malassezia occurs due to many predisposing factors like heat, moisture and occlusion of the skin by dressings, clothing or cosmetics (oil, talcum, etc.). ${ }^{26}$ In our study only $4.7 \%$ patients used talcum powder and $14.7 \%$ used oil over the body, so these factors were insignificant. The most important factor which was significant was the use of occlusive synthetic clothing in $39.3 \%$.

Because of the lipid requirement of the Malassezia species, PV is primarily found over the lipid rich areas of the body like chest, back, upper arm and face. ${ }^{22}$ Trunk was found to be the commonest site involved in our study similar to other studies.6,10,11,14-16,19,21,27 Whereas in few studies, neck was the commonest site involved..$^{7,8,12,13}$ In different studies conducted in Venezuela and Africa, the commonest site reported was face followed by upper trunk. ${ }^{28,29}$ In our study, the commonest site, trunk included upper chest and upper back which formed $52.70 \%$ of the total sites involved. In contrast to adolescent and adult age group, different studies have shown that face was the commonest site involved in children.7,9,23,24,30 Banerjee et al in their study found that in children below 12 years lower limb and buttock were significantly more commonly involved. ${ }^{10}$ In contrast, in our study, even in children (010 years), upper chest was the commonest site involved followed by upper back. Upper chest and upper back comprised the largest percentage of sites involved in patients up to 50 years old.

Skin dyspigmentation, either in the form of hypopigmentation or hyperpigmentation is most often the presenting complaint of patients with PV. The general concept is that in dark skinned individuals the lesions of PV are hypopigmented rather than hyperpigmented. ${ }^{31}$ Many studies in dark skinned Indian populations have concluded that hypopigmented lesions are commonest ranging from $74 \%$ to $90 \%$. $^{6-8,10,12,15,19,27}$ Even in 
Brazil, two studies showed that $62.9 \%$ and $93.3 \%$ of patients had hypopigmented lesions and in a study in Iran, $84.17 \%$ had hypopigmented macules. ${ }^{9,11,13}$ In contrast to these, in a study by Alijabre et al in Saudi Arabia, as high as onethird of dark skinned patients presented with hyperpigmented lesions. ${ }^{32}$ Whereas in our study, hypopigmented macules were present in $72.7 \%$ of patients, hyperpigmented macules in $26 \%$ and mixed variant (both hypo and hyperpigmented) in $15.3 \%$. The fact that the difference in color of lesions in different skin complexion is statistically insignificant, favours the theory stated by Alijabre et al where he found that there was no correlation between the pigmentary variations of PV and the type of skin. ${ }^{32}$

$\mathrm{PV}$ is asymptomatic in most of the cases, so it is considered to be more of cosmetic problem. But in our study, itching was present in $36.7 \%$ of the patients. Kaushik et al reported that $22 \%$ of patients with PV had prurtitus. ${ }^{33}$ In other studies, pruritus was an associated symptom in $25.5 \%, 30 \%, 35 \%, 47.27 \%, 48.3 \%$ and $51.1 \%$ of the patients. ${ }^{6-11}$
Malassezia yeasts have been associated in the pathogenesis of pityriasis capitis and seborrheic dermatitis besides $\mathrm{PV}^{34}$ The prevalence of seborrheic dermatitis has been found to be $10 \%$ (Ghosh et al), 11.6\% (Rao et al), 26.20\% (Kambil) and $31.9 \%$ (Banerjee et al) ${ }^{6,8,10,14}$ But in our study, the prevalence of seborrheic dermatitis was $44.67 \%$ which was high compared to previous studies.

In conclusion, PV is one of the commonest superficial fungal infections of the skin. But there is lack of detailed studies on PV which indicates a need of continuing research on the current profile of this problem in our community. When compared to several studies in the past, few factors like age group, sex, distribution, predisposing factors, prevalence of itching, color of lesions and prevalence of seborrheic dermatitis are changing. This shows that we need to do further studies in larger sample to prove these findings. Besides as this disease is a recurring chronic problem finding the common predisposing factors in our setting and counseling the patients about them could decrease the recurrence of this disease.

\section{REFERENCES}

1. Flores-Genuino RNS, Ray S, Bigby M, MoralesSánchez MA, Arkoncel M, Realubit-Serrano MAC, et al. Interventions for the treatment of pityriasis versicolor. Cochrane Database Syst Rev [Internet]. 2018 Jun [cited 2019 Aug 8]; 2018(6). Available from: https://www.ncbi.nlm.nih.gov/pmc/articles/ PMC6513390/

2. Hay RJ, Ashbee HR. Mycology. In Burns T, Breathnach S, Cox N, Griffiths C, editor. Rook's Textbook of Dermatology (8th ed.) UK: Wiley Blackwell 2010: 36.10-36.12.

3. Schwartz RA. Superficial fungal infections. Lancet 2004; 364: 1173-82.

4. Walker SL, Shah M, Hubbard VG, Pradhan HM, Ghimire M. Skin disease is common in rural Nepal: results of a point prevalence study. $\mathrm{Br} \mathrm{J}$ Dermatol 2008; 158: 334-8.

5. Mendez - Tovar LJ. Pathogenesis of dermatophytosis and tinea versicolor. Clin Dermatol 2010; 28: 185-9.

6. Ghosh SK, Dey SK, Saha I, Barbhuiya JN, Ghosh A, Roy AK . Pityriasis versicolor - a clinicomycological and epidemiological study from a tertiary care hospital. Indian J Dermatol 2008; 53: 182-5.

7. Sharma A, Rabha D, Choraria S, Hazarika D, Ahmed G, Hazarika NK. Clinicomycological profile of pityriasis versicolor in Assam. Indian J Pathol Microbiol 2016; 59: 159-65.

8. Gatha S Rao, Kuruvilla M, Kumar P, Vinod V. Clinicoepidemiological studies on tinea versicolor. Indian J Dermatol Venereol Leprol 2002; 68: 208-9.

9. Santana JO, de Azevedo FLA, Campos PC. Pityriasis versicolor: clinical-epidemiological characterization of patients in the urban area of
Buerarema-BA, Brazil. An Bras Dermatol 2013; 88: 216-21.

10. Banerjee S. Clinical Profile of pityriasis versicolor in a referral hospital of West Bengal. J Pak Assoc Dermatol 2011; 21: 248-52.

11. Morais PM , Cunha M da GS, Frota MZM. Clinical aspects of patients with pityriasis versicolor seen at a referral center for tropical dermatology in Manaus, Amazonas, Brazil. An Bras Dermatol 2010; 85: 797-803.

12. Shah A, Koticha A, Ubale M, Wanjare S, Mehta P, Khopkar U. Identification and speciation of Malassezia in patients clinically suspected of having pityriasis versicolor. Indian J Dermatol; 58: 239.

13. Talaee R, Katiraee F, Ghaderi M, Erami M, Kazemi Alavi A, Nazeri M. Molecular identification and prevalence of Malassezia species in Pityriasis Versicolor patients from Kashan, Iran. Jundishapur J Microbiol 2014; 7: e11561. Available from: http:// jjmicrobiol.com/en/articles/18746.html

14. Kambil SM. A clinical and epidemiological study of Pityriasis Versicolor. Int'l J Sci Stud 2017; 5: 155-59.

15. Archana B, Beena P, Kumar S. Study of the distribution of malassezia species in patients with pityriasis versicolor in Kolar Region, Karnataka. Indian J Dermatol 2015; 60: 321.

16. Heidrich D, Daboit TC, Stopiglia CDO, Magagnin CM, Vetoratto G, Amaro TG, et al. Sixteen years of pityriasis versicolor in metropolitan area of Porto Alegre, Southern Brazil. Rev Inst Med Trop São Paulo 2015; 57: 277-80. 
17. Badri $\mathrm{T}$, Hammami $\mathrm{H}$, Bzioueche $\mathrm{N}$, Zouari $\mathrm{B}$, Mokhtar I. Comparative clinical trial: fluconazole alone or associated with topical ketoconazole in the treatment of pityriasis versicolor. Tunis Med 2016; 94: 107-11.

18. Devendrappa K, Javed M. Clinical profile of patients with tinea versicolor. Int'l J Res Dermatol 2018; 4: 33-37.

19. Thayikkannu AB, Kindo AJ, Veeraragahavan M. Characterisation of Malassezia species and their clinical correlation in a tertiary healthcare centre in South India. J Acad Clin Microbiol 2013; 15: 49.

20. Tarazooie B, Kordbacheh P, Zaini F, Zomorodian K, Saadat F, Zeraati H, et al. Study of the distribution of Malassezia species in patients with pityriasis versicolor and healthy individuals in Tehran, Iran. BMC Dermatol 2004; 4: 5.

21. Kaur M, Narang T, Bala M, Gupte S, Aggarwal P, Manhas A. Study of the distribution of Malassezia species in patients with pityriasis versicolor and healthy individuals in Tertiary Care Hospital, Punjab. Indian J Med Microbiol 2013; 31: 270.

22. Gupta AK, Batra R, Bluhm R, Faergemann J. Pityriasis versicolor. Dermatol Clin 2003 ; 21: 41329.

23. Rijal A, Agrawal S, Bhattarai S. Prevalence and clinical features of pityriasis versicolor in children. Health Renaiss 2012; 10: 105-7.

24. Dwari B, Ram M, Jena D, Sengupta S. Pityriasis versicolor in the pediatric age group. Indian $J$ Dermatol Venereol Leprol 2005; 71: 259.

25. Gupta AK, Ryder JE, Nicol K, Cooper EA. Superficial fungal infections: an update on pityriasis versicolor, seborrheic dermatitis, tinea capitis, and onychomycosis. Clin Dermatol 2003; 21: 417-25.

26. Gupta D, Thappa DM. The enigma of color in tinea versicolor. Pigment Int'l 2014; 1: 32-5.

27. Ajaykrishnan, Thappa DM. Morphological and pigmentary variations of tinea versicolor in South Indian patients. Indian J Dermatol 2003; 48: 83.

28. Acosta Quintero ME, Cazorla Perfetti DJ. Clinicalepidemiological aspects of pityriasis versicolor (PV) in a fishing community of the semiarid region in Falcon State, Venezuela. Rev Iberoam Micol Dec; 21: 191-4.

29. Bélec L, Testa J, Bouree P. Pityriasis versicolor in the central African republic: a randomized study of 144 cases. Med Mycol 1991; 29: 323-9.

30. Terragni L, Lasagni A, Oriani A, Gelmetti C. Pityriasis versicolor in the pediatric age. Pediatr Dermatol 1991; 8: 9-12.

31. Kallini JR, Riaz F, Khachemoune A. Tinea versicolor in dark-skinned individuals. Int'l J Dermatol 2014; 53: 137-41.

32. Aljabre SHM, Alzayir AAA, Abdulghani M, Osman OO. Pigmentary changes of tinea versicolor in dark-skinned patients. Int'l J Dermatol 2001; 40: 273-5.

33. Kaushik A, Pinto HP, Bhat RM, Sukumar D, Srinath M K. A study of the prevalence and precipitating factors of pruritus in pityriasis versicolor. Indian Dermatol Online J 2014; 5: 223.

34. Gaitanis G, Magiatis P, Hantschke M, Bassukas ID, Velegraki A. The Malassezia genus in skin and systemic diseases. Clin Microbiol Rev 2012; 25: 10641. 